\title{
Socio-demographic, clinical and health facility- related predictors of delayed HIV diagnosis among patients newly diagnosed with HIV in Northwest Ethiopia: a multilevel analysis
}

Nurilign Abebe Moges ( $\square$ nure113@gmail.com )

Debre Markos University https://orcid.org/0000-0001-5912-1905

Yemane Berhane

Addis Continental Institute of Public health

Joshua Odunayo AKINYEMI

University of Ibadan

Micheal A. Okunlola

University of Ibadan

Olubukola Adeponle Adesina

University of Ibadan

\section{Research}

Keywords: delayed HIV diagnosis, HIV, multilevel analysis, Ethiopia

Posted Date: September 14th, 2020

DOI: https://doi.org/10.21203/rs.3.rs-74223/v1

License: (c) (i) This work is licensed under a Creative Commons Attribution 4.0 International License.

Read Full License 


\section{Abstract \\ Background}

Ethiopia recently implemented the 'test and treat' strategy for all HIV-infected individuals receiving a diagnosis at the health facility level. However, the impact of this policy in terms of timely HIV diagnosis and factors associated with it were not evaluated. Therefore, this study aimed to determine the magnitude and predictors of delayed HIV diagnosis among newly diagnosed people living with HIV in the northwest, Ethiopia.

\section{Methods}

In this cross-sectional study, a total of 759 newly diagnosed patients were recruited consecutively. The multistage sampling technique was employed to select health facilities and all newly diagnosed patients were included. Delayed HIV diagnosis was defined when there is an established AIDS-defining clinical condition (WHO clinical stage III or IV), irrespective of CD4 count. Data were entered into Epi-Data version 3.5 and exported to STATA version 14 for further analysis. Taking into account the nested structure of the data, multilevel logistic regression analysis has been employed. Four models containing variables of interest were fitted. Multivariate multilevel logistic regression analysis was performed to estimate the adjusted odds ratios (AOR) at a 95\% confidence interval (CI).

\section{Results}

A one-fourth of newly diagnosed HIV patients diagnosed at advanced disease stage. After controlling for other individual and health facility level factors, factors associated with delayed HIV diagnosis were: Patients who had completed secondary school or higher $(A O R=2.08,95 \% \mathrm{Cl}=1.06,4.08)$, patients who presented to health facilities with HIV symptoms ( $A O R=5.87,95 \% \mathrm{Cl}=3.57,9.62)$, being non-working functional status $(\mathrm{AOR}=4.80,95 \% \mathrm{Cl}=2.58,8.92)$ and $\mathrm{HIV}$ diagnosis at hospitals $(\mathrm{AOR}=2.16,95 \% \mathrm{Cl}=$ $1.08,4.31)$.

\section{Conclusion}

The magnitude of delayed HIV diagnosis was improved. In addition to individual-level factors, it is important to address health facility-related factors to improve earlier HIV diagnosis. Here, we recommend using both clinical and laboratory characteristics of a patient particularly, baseline CD4 count and viral load to identify patients diagnosed with advanced disease stage. Moreover, public health interventions are important targeted on factors associated with delayed HIV diagnosis.

\section{Background}


In Ethiopia, 729,089 individuals were estimated to be living with HIV by 2018. The annual case of new infections was estimated as 21,606 people and the annual AIDS-related death of 10,960 people in the same year [1, 2]. In 2017, only 426,000 were taking Antiretroviral Therapy (ART). Recognizing this low coverage of ART in the country and the prospect of failing to meet the 90-90-90 goal of the United Nations AIDS program (UNAIDS) by 2020 , the government endorsed the strategy of universal test and immediate treatment of HIV positive people in Ethiopia [3]. Still, Ethiopia's performance toward the UNAIDS 90-90-90 targets is low [4]. A recent systematic review and meta-analysis on the pooled prevalence of late presentation to HIV/AIDS care in Ethiopia revealed that about $52.89 \%$ of HIV patients present late for HIV care [5]. Close to half (45\%) of the general population in Ethiopia had never tested for HIV [6].

Early HIV diagnosis and presentation to healthcare facilitates of HIV positive people leads to the advantage of starting treatment as early as possible. Early initiation of ART will decrease disease progression and mortality and enhance HIV prevention [7-9]. However, HIV infected people delayed seeking health care and delay in initiating ART in East Africa is quite common [10-12]. The situation is similar in Ethiopia in which HIV infected people present to care and treatment within advanced disease stages [13-15]. This is worrisome because, patients who present late for HIV care are at increased risk of morbidity and mortality $[16,17]$.

Factors that have been reported to affecting entry into and engagement in the HIV continuum of care include the health status of individuals, flexibility of clinic policies, disrespectful treatment from service providers, stock-outs of supplies, stigma, and discrimination, alternate healing systems, diagnosed in hospital, distance to health facilities and poverty $[18,19]$. Socio-demographic factors associated with late HIV diagnosis include being male, older patients, patients with no formal education and being overweight [20-23]. Clinical, laboratory and behavioral factors such as fear of stigma, frequent use of alcohol and other substances, presence of symptoms at the time of HIV diagnosis and co-morbidities are also associated with late HIV diagnosis [5, 15, 19, 24, 25].

In Ethiopia, though there are several studies about the late presentation of HIV patients for HIV care [14, 26-30], many of the studies may not be generalized because all patients lately presented for HIV care may not necessary, diagnosed their HIV status late. Late presentation to care may occur even though the patients are aware of the HIV status due to several reasons such as fear of stigma [25]. In addition to this, many previously published studies $[15,31,32]$ used a small sample size, were single-site study, used secondary data, and were carried out before test and treat strategy was implemented. So that whether or not test and treat strategy improved HIV test uptake and avoid delayed HIV diagnosis was examined. Moreover, this study investigated contextual and individual-level factors affecting timely HIV diagnosis of HIV patients over multiple clinical sites. To minimize the confounding effects of nested data over multiple clinical sites, we have employed advanced statistical analysis techniques (multilevel logistic regression) that could improve the limitation of previous studies. Therefore, the study aimed to determine the prevalence and factors associated with delayed HIV diagnosis among newly identified people living with HIV in Ethiopia. 


\section{Methods And Materials}

\section{Study settings and populations}

The study was conducted in health facilities from three administrative zones of Amhara regional state, northwest Ethiopia. A total of 24 health facilities ( 9 hospitals and 15 health centers) were selected. Five hospitals and six health centers from East Gojjam Zone, two hospitals and six health centers from West Gojjam Zone, and Bahir Dar city administrations two hospitals and three health centers were selected. The region has an adult HIV prevalence of $1.2 \%$ which was higher than the national average $(0.9 \%)$ in 2016 [33].

All newly diagnosed HIV positive individuals in the HIV treatment centers of the 24 health facilities who consented to participate in the study were recruited into the study between December $1^{\text {st }}, 2018$ and July 30,2019 . The health facilities were included based on an average patient flow of three to five new cases per month. Participants were eligible if they were 18 years old or over, newly diagnosed with HIV and had no prior exposure to ART. The target population was all newly diagnosed HIV-positive patients in the three administrative zones.

\section{Design and sample size}

The study design was cross-sectional. The sample size was calculated using a formula for a single population proportion. The proportion of late presenters to HIV care was taken from a previous study in Ethiopia, which was $52.89 \%$ [5]. Using the formula;

$\left(Z_{a / 2}\right)^{2}(P)(p-q) / w^{2} ;$ where $Z_{a / 2}=1.96, q=47.11 \%, p=52.89 \%$ and marginal error $(w)=0.05$. Total $=383$

And considering a non-response rate of $10 \%$ and a design effect of two, a total of 844 participants were required.

\section{Sampling procedures}

Three administrative zones were selected purposively. Then a total of 71 health facilities (13 hospitals and 58 health centers) providing ART services were identified in the three zones. Health facilities were clustered based on average patient flow as "high load" $\geq 3$ new patients per month and "low load" $<3$ new patients per month. A total sample of 844 was distributed for 24 health facilities that fulfilled the selection criteria (fig 1 ).

Fig 1: Sampling techniques of delayed HIV diagnosis amongnewly diagnosed people living with HIV in northwest Ethiopia, 2019

\section{Data collection tools and procedures}

Data collection tools were developed from a review of similar literature on the subject matter $[14,15,26-$ $32,34,35]$. Data were collected using exit interview techniques via interviewer-administered 
questionnaires. Interviews were conducted in a quiet separate room after obtaining written informed consent. Data collectors were nurses who have received training on HIV treatment guidelines and working in the HIV clinic. All newly diagnosed HIV positive individuals were included consecutively until the required sample size was achieved.

\section{Variables and definitions}

Delayed HIV diagnosis was defined following the European Late Presenter Consensus working group as a patient who presents for care when there is an established AIDS-defining clinical condition (stage III/IV) irrespective of CD4 count [36]. Independent variables were categorized into individual and community level factors. Individual-level variables included: age, sex, religion, ethnicity, marital status, educational status, employment status, occupation, wealth status, opportunistic infections, body mass index (BMI), functional status, pregnancy status, any current health complaints. Other individual-level variables were alcohol use, disclosure status, HIV test history, number of sexual partners, condom use, HIV and ART related Knowledge, level of perceived stigma. Health facility-related variables included types of health facility, zones, residence and distance from the health facility.

\section{Data processing and analysis}

Data were entered into Epi-Data version 3.5 and exported to STATA version 14 for further analysis. Taking into account the nested structure of the data, multilevel logistic regression analysis has been employed. Four models containing variables of interest were fitted using STATA version 14. Model I (Empty model) was fitted without independent variables to test random variability in the intercept and to estimate the intra-class correlation coefficient (ICC). Model II examined the effects of individual-level variables, Model III examined the effect of health facility level variables and Model IV examined the effects of both individual and health facility level characteristics simultaneously. The random effects are the measures of variation in delayed HIV diagnosis across communities expressed as ICC and proportional change in variance (PCV). Akaike's Information Criterion (AIC) and Bayesian Information Criterion (BIC) were used to choose a model that best explains the data and the model with low AIC value was taken.

The predicting ability of the model (model accuracy) was evaluated using the Receiver Operating Characteristic (ROC) and area under the curve. These indicated that in model III in which only individuallevel variables were fitted it was $81.90 \%$ while it was $84.23 \%$ in the final model (IV) that included the health facility level variables. Multivariate multilevel logistic regression analysis was performed to estimate the adjusted odds ratios (AOR) at a 95\% confidence interval (Cl).

\section{Results}

\section{Background characteristics of study participants}

Prevalence of delayed HIV diagnosis was $25 \%$ (95\% Cl=22-28\%). Four hundred thirty-six $(57.4 \%)$ of the study participants were females. The majority $(659,86.82 \%)$ were working functional status while $36.5 \%$ 
of study participants presented with at least one type of health complaint. About $67.6 \%$ of them tested for HIV via providers' initiation and $67.3 \%$ had never tested for HIV. More than $62 \%$ of the study participants had a good level of HIV-related knowledge (Table 1).

\section{Health facility-related characteristics}

Three hundred thirty-one (43.6\%) were from the East Gojjam zone and $50.2 \%$ were from hospitals. The majority $(577,76 \%)$ were living in urban areas and $592(78 \%)$ lived in less than one-hour walking distance from the health facility (Table 2).

Table 2: Health facility-level characteristics of newly diagnosed people living with HIV in Northwest Ethiopia, 2019

\begin{tabular}{|ll|}
\hline Characteristics & Frequency (\%) \\
\hline Zone & $331(43.6)$ \\
East Gojjam & $170(22.4)$ \\
Best Gojjam & $258(34)$ \\
\hline Health facility type & $378(49.8)$ \\
Health center & $381(50.2)$ \\
Hospital & \\
\hline Residence of the patient & $182(24)$ \\
Rural & $577(76)$ \\
Urban & \\
\hline Distance from a health facility & $592(78)$ \\
$<1$ hour walking & $167(22)$ \\
$>=1$ hour walking & \\
\hline
\end{tabular}

\section{Factors associated with delayed HIV diagnosis}

In the multilevel logistic regression analysis, the results of the empty model (Model I) depicted that there was statistically significant variability in the odds of delayed HIV diagnosis (ICC $=9.26 \%$ ) which is the total variance in the delayed HIV diagnosis was attributed to differences between communities. In Model II only individual-level variables were added. The results showed that educational status of secondary school or higher $(A O R=1.99,95 \% \mathrm{Cl}=1.04,3.83)$, history of test for HIV ( $A O R=1.63,95 \% \mathrm{Cl}=1.01,2.63)$, poor functional status $(\mathrm{AOR}=4.75,95 \% \mathrm{Cl}=2.56,8.82)$ and presenting with symptoms ( $\mathrm{AOR}=5.69,95 \%$ $\mathrm{Cl}=3.47,9.31)$ were significantly associated with delayed HIV diagnosis. In Model III, only health facility- 
level variables were added. The result revealed that newly diagnosed people living with HIV who sought HIV care at hospitals were almost twice to be delayed to diagnose HIV compared to those in health centers (AOR=1.97, 95\% Cl=1.15, 3.34). As shown by the proportional change variance (PCV), $47.06 \%$ of the variance in delayed HIV diagnosis across participants was explained by the health facility level characteristics.

In the final model (IV), both the individual and health facility level characteristics were included simultaneously. After controlling for other individual and health facility level factors, people who had completed secondary school or higher were 2.08 times more likely to diagnose their HIV status late compared to those non-educated $(\mathrm{AOR}=2.08,95 \% \mathrm{Cl}=1.06,4.08)$, people who presented to health facilities with symptoms and poor functional status were $87 \%$ and $80 \%$ more likely to be delayed in HIV diagnosis compared to their counterparts ( $\mathrm{AOR}=5.87,95 \% \mathrm{Cl}=3.57,9.62)$ and $(\mathrm{AOR}=4.80,95 \% \mathrm{Cl}=2.58,8.92)$. Moreover, patients who were diagnosed with their HIV status at hospitals were 2.16 times more likely to be late to know their HIV status compared with those diagnosed in health centers (AOR=2.16, 95\% $\mathrm{Cl}=1.08,4.31$ ) (Table 3 ).

\section{Results of random effect analysis}

In model I (Empty model) the intra-class correlation coefficient (ICC) was 9.26\%, in model II (12.30\%), in model III (5.45) and model IV (7.70\%). The random effects are the measures of variation in delayed HIV diagnosis across communities expressed as ICC and proportional change in variance (PCV). Akaike's Information Criterion (AIC) and Bayesian Information Criterion (BIC) were used to choose a model that best explains the data and the model with low AIC value was taken (Table 4).

\section{Table 4: Random effect analysis of delayed HIV diagnosis among newly identified HIV patients in Northwest Ethiopia}

\begin{tabular}{|lllll|}
\hline Random effect & Model 1 & Model 2 & Model 3 & Model 4 \\
\hline Community variance (SE) & $0.34^{\star *}(0.15)$ & $0.46^{\star *}(0.24)$ & $0.189 *(0.12)$ & $0.27^{\star}(0.18)$ \\
\hline ICC (\%) & 9.26 & 12.30 & 5.45 & 7.70 \\
\hline PCV (\%) & Ref & -35.29 & 47.06 & 18.52 \\
\hline Log likelihood & -408.22 & -275.22 & -403.77 & -271.19 \\
\hline AIC & 820.44 & 600.56 & 821.56 & 602.39 \\
\hline BIC & 829.71 & 713.39 & 853.98 & 737.79 \\
\hline
\end{tabular}

ICC=intra-class correlation coefficient, $\mathrm{PCV}=$ proportional change in variance, $\mathrm{AIC}=$ Akakian Information Criteria, BIC= Bayesian Information Criteria

* Significant at P-value $<0.05$ and ** Significant at P-value $<0.001$ 


\section{Discussion}

This study revealed that one-fourth of newly identified people living with HIV were diagnosed at an advanced disease stage. Both individual and health facility level factors were found to be associated with delayed HIV diagnosis.

The magnitude of delayed HIV diagnosis was consistent with previous studies from Turkey [21] and China [34]. However, in the current study we have observed that there was an improvement of earlier HIV diagnosis before the advancement of disease compared to reports of previous studies in Ethiopia [5, 14, $15,26]$, China $[19,24]$, and South Africa [20,37]. The possible explanations may be time differences between the present and previous studies in which there was a tendency of improved timely HIV diagnosis $[12,21,24]$. The other reasons may be due to previous studies that defined delayed HIV diagnosis using CD4 count in addition to WHO clinical stage while this study used only the WHO clinical stage due to the new guidelines $[3,38]$. This may underestimate the magnitude of delayed HIV diagnosis. Indeed, the WHO recommended using clinical stages 3 and 4 to define the advanced disease stage as an alternative to CD 4 count [38]. Resuming baseline immunological measurement is important since CD 4 count testing still has an important role to play in assessing the baseline risk of disease progression [17, 39]. Therefore, in the absence of baseline CD4 level determination, the accurate clinical-stage determination should be improved via training of healthcare providers. Moreover, the limitation of WHO clinical staging to indicate advanced disease stage over CD4 count determination should be acknowledged. A Validation study is recommended to determine the sensitivity and specificity of the WHO clinical stage over immunological measurements.

Baseline clinical profiles of patients such as poor functional status and presented having symptoms at first HIV diagnosis were associated with delayed HIV diagnosis, which was similar to previous reports [5, 15, 29-31]. Strengthening existing HIV testing programs including healthcare provider-initiated HIV testing and counseling services should be improved. Furthermore, implementing new programs such as self-HIV testing, house-to-house HIV testing, and resuming HIV testing campaigns would improve timely HIV diagnosis. The reasons for the symptomatic presentation of patients may be attributed to a lack of consistent commitment to implementing community awareness, voluntary counseling, and testing campaigns by the Ethiopian government [4].

This study revealed that a higher level of education was associated with delayed HIV diagnosis, which was similar to the results of other previous studies $[29,40]$. However, this finding was contrary to other studies that reported an association between a lower level of education and delayed HIV diagnosis [20, $21,32,41]$. The reasons for the observed discrepancies between delayed HIV diagnoses and the level of education are unknown but may be related to fear of stigma. One study in Ethiopia reported that more educated people are doubtful of HIV test results and repeat it in other health facilities [42]. Such repeat HIV tests may also contribute to delay because repeat HIV-positive testing is associated with a delay in linkage to care. In line with this, patients having a history of HIV test was found to be one of the individual-level factors associated with delayed HIV diagnosis. Interventions targeted at reducing HIV 
related stigma are highly relevant since a high level of HIV related stigma has an impact on a timely presentation for HIV care $[5,25]$. The findings may warrant further investigation of the reason for delayed HIV diagnosis among educated people.

The odds of delayed HIV diagnosis were twice increased among patients diagnosed in hospitals compared to those diagnosed in health centers, which was similar to previous studies $[19,37]$. The possible explanation may be most patients with AIDS-defining illness visited hospitals than primary healthcare settings. This might be due to the chains of a referral system from primary to secondary or tertiary units of the healthcare system in Ethiopia. Moreover, previous studies indicated that HIV patients with co-morbid chronic illnesses present late for HIV care $[5,28,29]$. This may explain why most of the chronic cases are managed at the hospital level. The finding suggested that there should be programs that should be targeting in hospitals and individuals with chronic illness to ensure timely HIV diagnosis and management.

\section{Limitations Of The Study}

Though the study was the first to employ multilevel factors analysis, which contributes to the literature on delayed HIV diagnosis, the findings should be interpreted within its limitations. In this cross-sectional survey, we were not able to ascertain the causality of associations with delayed HIV diagnosis. Although CD4 counts are important to identify those who presented with advanced HIV disease, we were not able to use CD 4 count to define delayed HIV diagnosis so that the magnitude of delayed HIV diagnosis may be underestimated.

\section{Conclusion}

The magnitude of delayed HIV diagnosis was improved. Here, we recommend using both clinical and laboratory characteristics of a patient particularly, baseline CD 4 count and viral load to identify patients diagnosed with advanced disease stage. In addition to individual-level factors, it is important to address health facility-related factors to improve earlier HIV diagnosis. We recommend further large scale studies on the acceptability of new strategies such as self-HIV testing, house-to-house HIV testing and resuming HIV testing campaigns which would improve timely HIV diagnosis. Moreover, public health interventions are important targeted on factors associated with delayed HIV diagnosis.

\section{Abbreviations}

HAART Highly Active Antiretroviral Therapy

HIV Human immunodeficiency virus

PLHIV People Ling with HIV

WHO World Health Organization 


\section{Declarations}

\section{Ethics approval and consent to participate}

Institutional review board (IRB) of University College Hospital, University of Ibadan, Ibadan, Nigeria on $17 / 09 / 2018$ with reference number UI/EC/18/0463 and Debre Markos University with reference number HSC/30/02/2011 have approved.

\section{Consent for publication}

Not applicable

\section{Availability of data and materials}

The datasets used and/or analyzed during the current study are available from the corresponding author on reasonable request.

\section{Competing interests}

The authors declared that there is no competing of interest

\section{Funding}

This study was supported by the Pan African University (PAU), a continental initiative of the African Union Commission (AU), Addis Ababa, Ethiopia, as part of the Ph.D. program in Reproductive Health Sciences. NAM received the funding from PAU. The University had no role in the study design and decision to publish or preparation of the manuscript.

\section{Authors' contributions}

NAM, OAA, MAO and YB contributed equally to the design of the study. JOA assisted in the data analysis, NAM and OAA drafted the manuscript and all the authors revised and approved the manuscript.

\section{Acknowledgments}

We are grateful to African Union Commission (AU) for funding this study. We also extend our gratitude to our research assistants all study participants who participated in this study.

\section{References}

1. EHNRI, F., HIV Related Estimates and Projections for Ethiopia. Addis Ababa: FMoH, 2012: p. 6-14.

2. FMOH, E., HIV Related Estimates and Projections for Ethiopia, in Addis Ababa: EPHI 2017.

3. Ethiopia, F.M.o.H., National guidelines for comprehensive HIV prevention, care and treatment, A.A.M.o. Health, Editor. 2017. 
4. Hailay Gesesew, P.W., KifleWoldemichael and Lillian Mwanri et al, Improving the UNAIDS 90-90-90 Treatment Targets: Solutions Suggested from a Qualitative Study of HIV Patients, Community Advocates, HealthWorkers and Program Managers in Jimma, Southwest Ethiopia. Int. J. Environ. Res. Public Health, 2020. 2020(17).

5. Getaneh Mulualem Belay, A.E.a.A.D.A., Late presentation of HIV positive adults and its predictors to HIV/AIDS care in Ethiopia: a systematic review and meta-analysis. BMC Infect Dis, 2019.

6. Lifson, A.R., et al., Failure to test for HIV in rural Ethiopia: knowledge and belief correlates and implications for universal test and treat strategies. Journal of the International Association of Providers of AIDS Care (JIAPAC), 2013. 12(5): p. 306-311.

7. Cotton, M.F., et al., Early limited antiretroviral therapy is superior to deferred therapy in HIV-infected South African infants: results from the CHER (Children with HIV Early antiRetroviral) Randomized Trial. Lancet, 2013. 382(9904): p. 1555-1563.

8. Grinsztejn, B., et al., Effects of early versus delayed initiation of antiretroviral treatment on clinical outcomes of HIV-1 infection: results from the phase 3 HPTN 052 randomised controlled trial. The Lancet infectious diseases, 2014. 14(4): p. 281-290.

9. Koenig, S.P., et al., Same-day HIV testing with initiation of antiretroviral therapy versus standard care for persons living with HIV: A randomized unblinded trial. PLoS Med, 2017. 14(7): p. e1002357.

10. Agaba, P., et al., Patients who present late to HIV care and associated risk factors in Nigeria. HIV medicine, 2014. 15(7): p. 396-405.

11. Fomundam, H.N., et al., Prevalence and predictors of late presentation for HIV care in South Africa. South African Medical Journal; Vol 107, No 12 (2017), 2017.

12. Lahuerta, M., et al., Advanced HIV disease at entry into HIV care and initiation of antiretroviral therapy during 2006-2011: findings from four sub-saharan African countries. Clinical infectious diseases, 2013. 58(3): p. 432-441.

13. Mulissa, Z., D. Jerene, and B. Lindtjørn, Patients present earlier and survival has improved, but preART attrition is high in a six-year HIV cohort data from Ethiopia. PloS one, 2010. 5(10): p. e13268.

14. Gesesew, H.A., et al., Late presentation for HIV care in Southwest Ethiopia in 2003-2015: prevalence, trend, outcomes and risk factors. BMC infectious diseases, 2018. 18(1): p. 59.

15. Assen, A., et al., Late presentation for diagnosis of HIV infection among HIV positive patients in South Tigray Zone, Ethiopia. BMC public health, 2016. 16(1): p. 558.

16. Belay, H., et al., Effect of late HIV diagnosis on HIV-related mortality among adults in general hospitals of Central Zone Tigray, northern Ethiopia: a retrospective cohort study. HIV/AIDS (Auckland, NZ), 2017. 9: p. 187.

17. Abraham Siika, L.M., Mutsa Bwakura-Dangarembizi et al, Late Presentation With HIV in Africa: Phenotypes, Risk, and Risk Stratification in the REALITY Trial. Clinical Infectious Diseases, 2018. 66(2).

18. Layer, E.H., et al., Multi-Level Factors Affecting Entry into and Engagement in the HIV Continuum of Care in Iringa, Tanzania. PLoS ONE, 2014. 9(8): p. e104961. 
19. Xi Hu1, Bingyu Liang1,2†, Chongxing Zhou3t, Junjun Jiang, HIV late presentation and advanced HIV disease among patients with newly diagnosed HIV/AIDS in Southwestern China: a large-scale cross-sectional study. AIDS research and therapy, 2019. 16(6).

20. Olufunso O. Sogbanmu, M., b, Daniel T. Goon, DTechc, Larry C. Obi, PhDd, Ben C. Iweriebor, PhDa,b, Uchechukwu N. Nwodo, PhDa,b, Anthony I. Ajayi, PhDe, *, Anthony I. Okoh, PhDa, Socio-demographic and clinical determinants of late presentation among patients newly diagnosed with HIV in the Eastern Cape, South Africa. medicin 2019. 98(8).

21. al, H.K.K.e., LATE PRESENTATION AMONG PATIENTS WITH HUMAN IMMUNODEFICIENCY VIRUS INFECTION IN TURKEY. Cent Eur J Public Health, 2019. 27(3).

22. Hønge, B.L., et al., High prevalence and excess mortality of late presenters among HIV-1, HIV-2 and HIV-1/2 dually infected patients in Guinea-Bissau-a cohort study from West Africa. The Pan African medical journal, 2016. 25.

23. Drain, P.K., et al., Risk factors for late-stage HIV disease presentation at initial HIV diagnosis in Durban, South Africa. PloS one, 2013. 8(1): p. e55305.

24. Jing Xie1, Evelyn Hsieh3, Meng-qing Sun4, Huan-ling Wang1, Wei Lv1, Hong-wei Fan1, Tai-sheng Li1,2, Delays in HIV diagnosis and associated factors among patients presenting with advanced disease at a tertiary care hospital in Beijing, China. PLoS One, 2017. 12(8).

25. Gesesew, H.A., et al., Significant association between perceived HIV related stigma and late presentation for HIVIAIDS care in low and middle-income countries: A systematic review and metaanalysis. PloS one, 2017. 12(3): p. e0173928.

26. Nash, D., et al., Factors associated with initiation of antiretroviral therapy in the advanced stages of HIV infection in six Ethiopian HIV clinics, 2012 to 2013. Journal of the International AIDS Society, 2016. 19(1): p. 20637.

27. Gesesew, H., et al., The prevalence and associated factors for delayed presentation for HIV care among tuberculosis/HIV co-infected patients in Southwest Ethiopia: a retrospective observational cohort. Infectious diseases of poverty, 2016. 5(1): p. 96.

28. Gelaw, Y.A., et al., Determinants of late presentation to HIV/AIDS care in Southern Tigray Zone, Northern Ethiopia: an institution based case-control study. AIDS research and therapy, 2015. 12(1): p. 40.

29. Gesesew, H.A., F.A. Tesfamichael, and B.T. Adamu, Factors affecting late presentation for HIV/AIDS care in southwest Ethiopia: a case control study. Public Health Research, 2013. 3(4): p. 98-107.

30. Abaynew, Y., A. Deribew, and K. Deribe, Factors associated with late presentation to HIV/AIDS care in South Wollo ZoneEthiopia: a case-control study. AIDS research and therapy, 2011. 8(1): p. 8.

31. Aniley, A.B., et al., Factors associated with late Human Immunodeficiency Virus (HIV) diagnosis among peoples living with it, Northwest Ethiopia: hospital based unmatched case-control study. BMC public health, 2016. 16(1): p. 1076.

32. Beyene, M.B. and H.B. Beyene, Predictors of late HIV diagnosis among adult people living with HIV/AIDS who undertake an initial CD4 T cell evaluation, Northern Ethiopia: A Case-control study. 
PloS one, 2015. 10(10): p. e0140004.

33. (CSA), C.S.A., Ethiopia Demographic and Health Survey 2016 HIV Report. 2016: Addis Ababa, Ethiopia, and Rockville, Maryland, USA: CSA and ICF.

34. Cheng, W., et al., Late presentation of HIV infection: prevalence, trends, and the role of HIV testing strategies in Guangzhou, China, 2008-2013. BioMed research international, 2016. 2016.

35. Ndiaye, B., et al., Factors associated with presentation to care with advanced HIV disease in Brussels and Northern France: 1997-2007. BMC infectious diseases, 2011. 11(1): p. 11.

36. Antinori, A., et al., Late presentation of HIV infection: a consensus definition. HIV medicine, 2011. 12(1): p. 61-64.

37. Fomundam, H., et al., Prevalence and predictors of late presentation for HIV care in South Africa. South African Medical Journal, 2017. 107(12): p. 1058-1064.

38. WHO, THE USE OF ANTIRETROVIRAL DRUGS FOR TREATING AND PREVENTING HIV INFECTION PREVENTING HIV INFECTION, 2016 RECOMMENDATIONS FOR A PUBLIC HEALTH APPROACH, W.L.C.-i.-P. Data, Editor. 2016, WHO: Geneva 27, Switzerland.

39. WHO, Guideline on when to start antiretroviral therapy and on pre-exposure prophylaxis for HIV. 2015.

40. Mujugira, A., et al., Delay of Antiretroviral Therapy Initiation is Common in East African HIV-Infected Individuals in Serodiscordant Partnerships. Journal of acquired immune deficiency syndromes (1999), 2014. 66(4): p. 436-442.

41. Geng, E.H., et al., Failure to initiate antiretroviral therapy, loss to follow-up and mortality among HIVinfected patients during the pre-ART period in Uganda. Journal of acquired immune deficiency syndromes (1999), 2013. 63(2): p. e64.

42. Kulkarni, S., et al., "Testing, Testing": Multiple HIV-Positive Tests among Patients Initiating Antiretroviral Therapy in Ethiopia. Journal of the International Association of Providers of AIDS Care (JIAPAC), 2017. 16(6): p. 546-554.

\section{Tables}

Table 1: Individual-level characteristics of newly diagnosed people living with HIV in Northwest Ethiopia, 2019 


\begin{tabular}{|c|c|}
\hline Characteristics & Frequency (\%) \\
\hline \multicolumn{2}{|l|}{ WHO clinical stage } \\
\hline $1 / I I$ & $569(75)$ \\
\hline III/IV & $190(25)$ \\
\hline \multicolumn{2}{|l|}{ Sex } \\
\hline Male & $323(42.6)$ \\
\hline Female & $436(57.4)$ \\
\hline \multicolumn{2}{|l|}{ Age in years } \\
\hline $18-24$ & $106(14)$ \\
\hline $25-34$ & $350(46.1)$ \\
\hline$>=35$ & 303 (39.9) \\
\hline \multicolumn{2}{|l|}{ Marital status } \\
\hline Single & $228(30)$ \\
\hline Married & $278(36.6)$ \\
\hline Divorced & $202(26.6)$ \\
\hline Widowed & $51(6.7)$ \\
\hline \multicolumn{2}{|l|}{ Educational status } \\
\hline No formal education & $282(37.2)$ \\
\hline Primary education & $249(32.8)$ \\
\hline Secondary or higher & $228(30.0)$ \\
\hline \multicolumn{2}{|l|}{ Wealth quintile status } \\
\hline Poorest & $168(22.13)$ \\
\hline Poorer & $136(17.92)$ \\
\hline Middle & 149 (19.63) \\
\hline Wealthier & $158(20.82)$ \\
\hline Wealthiest & $148(19.50)$ \\
\hline \multicolumn{2}{|l|}{ Functional status } \\
\hline Working & $659(86.82)$ \\
\hline Ambulatory/bedridden & $100(13.18)$ \\
\hline
\end{tabular}




\begin{tabular}{|ll|} 
Yes & $277(36.5)$ \\
\hline Po & $482(63.5)$ \\
HIV Positive & $229(30.7)$ \\
HIV negative & $87(11.7)$ \\
Unknown & $429(57.6)$ \\
\hline Ever test for HIV & \\
Yes & $248(32.67)$ \\
No & $511(67.33)$ \\
\hline Testing modality & \\
Provider initiated & $513(67.6)$ \\
Self-initiated & $246(32.4)$ \\
\hline Knowledge of HIV prevention & \\
\hline Good & $516(67.98)$ \\
Poor & $243(32.02)$ \\
\hline Knowledge of HIV mode of transmission & \\
Good & $477(62.85)$ \\
Poor & $282(37.1 .5)$ \\
\hline Knowledge about ART & $478(62.80)$ \\
Good & $281(37.20)$ \\
\hline Poor & \\
\hline
\end{tabular}

Table 3: Multilevel logistic regression analysis of factors associated with delayed HIV diagnosis among newly identified HIV patients in Northwest Ethiopia 


\begin{tabular}{|c|c|c|c|c|}
\hline $\begin{array}{l}\text { Characteristics } \\
\text { Fixed effect }\end{array}$ & Model & $\begin{array}{l}\text { Model II } \\
\text { AOR }(95 \% \mathrm{Cl})\end{array}$ & $\begin{array}{l}\text { Model III } \\
\text { AOR }(95 \% \mathrm{Cl})\end{array}$ & $\begin{array}{l}\text { Model IV } \\
\text { AOR }(95 \% \mathrm{Cl})\end{array}$ \\
\hline \multicolumn{5}{|l|}{ Sex } \\
\hline Male & & 1 & & 1 \\
\hline Female & & $0.76(0.46,1.24)$ & & $0.75(0.46,1.24)$ \\
\hline \multicolumn{5}{|l|}{ Marital status } \\
\hline Single & & 1 & & 1 \\
\hline Married & & $1.44(0.79,2.62)$ & & $1.40(0.46,1.24)$ \\
\hline Divorced & & $0.62(0.32,1.19)$ & & $0.61(0.31,1.16)$ \\
\hline Widow/d & & $0.77(0.74,3.79)$ & & $0.67(0.24,1.84)$ \\
\hline \multicolumn{5}{|l|}{ Age in years } \\
\hline $18-24$ & & 1 & & 1 \\
\hline $25-34$ & & $1.68(0.74,3.79)$ & & $1.7(0.76,3.89)$ \\
\hline$>=35$ & & $1.91(0.82,4.48)$ & & $1.84(0.78,4.32)$ \\
\hline \multicolumn{5}{|l|}{ Educational status } \\
\hline No formal education & & 1 & & 1 \\
\hline Primary education & & $1.61(0.89,2.88)$ & & $1.68(0.92,3.04)$ \\
\hline Secondary or higher & & $1.99(1.04,3.83) \star$ & & $2.08(1.06,4.08)^{\star}$ \\
\hline \multicolumn{5}{|l|}{ Wealth quintile } \\
\hline Poorest & & 1 & & 1 \\
\hline Poorer & & $1.16(0.54,2.46)$ & & $1.21(0.57,2.57)$ \\
\hline Middle & & $0.99(0.46,2.15)$ & & $0.92(0.43,2.01)$ \\
\hline \multirow[t]{2}{*}{ Wealthier Wealthiest } & & $0.95(0.44,2.05)$ & & $0.83(0.38,1.81)$ \\
\hline & & $0.67(0.29,1.53)$ & & $0.62(0.26,1.43)$ \\
\hline \multicolumn{5}{|l|}{ Ever test for HIV } \\
\hline Yes & & $1.63(1.01,2.63)^{\star}$ & & $1.53(0.94,2.47)$ \\
\hline No & & 1 & & 1 \\
\hline \multicolumn{5}{|l|}{ Testing modality } \\
\hline Provider initiated & & $1.45(0.32,1.62)$ & & $1.40(0.78,2.49)$ \\
\hline Self-initiated & & 1 & & 1 \\
\hline
\end{tabular}




\begin{tabular}{|c|c|c|}
\hline \multicolumn{3}{|c|}{ Partner HIV status } \\
\hline HIV Positive & 1 & 1 \\
\hline HIV negative & $0.72(0.32,1.62)$ & $0.68(0.30,1.52)$ \\
\hline Unknown & $1.49(0.83,2.69)$ & $1.44(0.80,2.57)$ \\
\hline \multicolumn{3}{|c|}{ Functional status } \\
\hline Working & 1 & 1 \\
\hline Non-working & $\begin{array}{l}4.75 \\
(2.56,8.82)^{* *}\end{array}$ & $\begin{array}{l}4.80 \\
(2.58,8.92)^{\star *}\end{array}$ \\
\hline \multicolumn{3}{|c|}{ Nutritional status } \\
\hline Malnourished & 1 & 1 \\
\hline Normal & $0.86(0.52,1.42)$ & $0.85(0.51,1.40)$ \\
\hline \multicolumn{3}{|c|}{$\begin{array}{l}\text { Knowledge of HIV } \\
\text { transmission }\end{array}$} \\
\hline \multicolumn{3}{|l|}{ Good } \\
\hline Poor & $1.05(0.58,1.88)$ & $1.06(0.59,1.89)$ \\
\hline \multicolumn{3}{|c|}{ Knowledge of HIV prevention } \\
\hline \multicolumn{3}{|l|}{ Good } \\
\hline \multirow[t]{2}{*}{ Poor } & $1.02(0.53,1.95)$ & $1.07(0.38,2.03)$ \\
\hline & 1 & 1 \\
\hline \multicolumn{3}{|c|}{ Knowledge of ART } \\
\hline Good & $0.68(0.38,1.23)$ & $0.69(0.38,1.26)$ \\
\hline Poor & 1 & 1 \\
\hline \multicolumn{3}{|c|}{ Present with symptoms } \\
\hline Yes & $\begin{array}{l}5.69 \\
(3.47,9.31)^{\star \star}\end{array}$ & $\begin{array}{l}5.87 \\
(3.57,9.62) \star \star\end{array}$ \\
\hline No & 1 & 1 \\
\hline \multicolumn{3}{|c|}{ Have a cell phone } \\
\hline Yes & 1 & 1 \\
\hline No & $0.71(0.36,1.38)$ & $0.74(0.37,1.45)$ \\
\hline \multicolumn{3}{|l|}{ Zone } \\
\hline East Gojjam & & $1.11(0.56,2.22)$ \\
\hline
\end{tabular}




\begin{tabular}{|lll|} 
West Gojjam & $0.84(0.40,1.79)$ & $0.67(0.25,1.78)$ \\
Bahir Dar city & 1 & 1 \\
\hline Facility type & & 1 \\
Health center & 1 & $2.16(1.08,4.31)^{\star}$ \\
Hospital & 1.97 & \\
Residence & $(1.15,3.34)^{\star}$ & 1 \\
Rural & & $1.05(0.55,2.00)$ \\
Urban & 1 & \\
\hline Distance from a health facility & $0.93(0.59,1.46)$ & 1 \\
$<1$ hour walking & & $1.30(0.74,2.27)$ \\
\hline$>1$ hour walking & 1 & \\
\end{tabular}

* Significant at P-value $<0.05$ and ** Significant at P-value $<0.001$

\section{Figures}




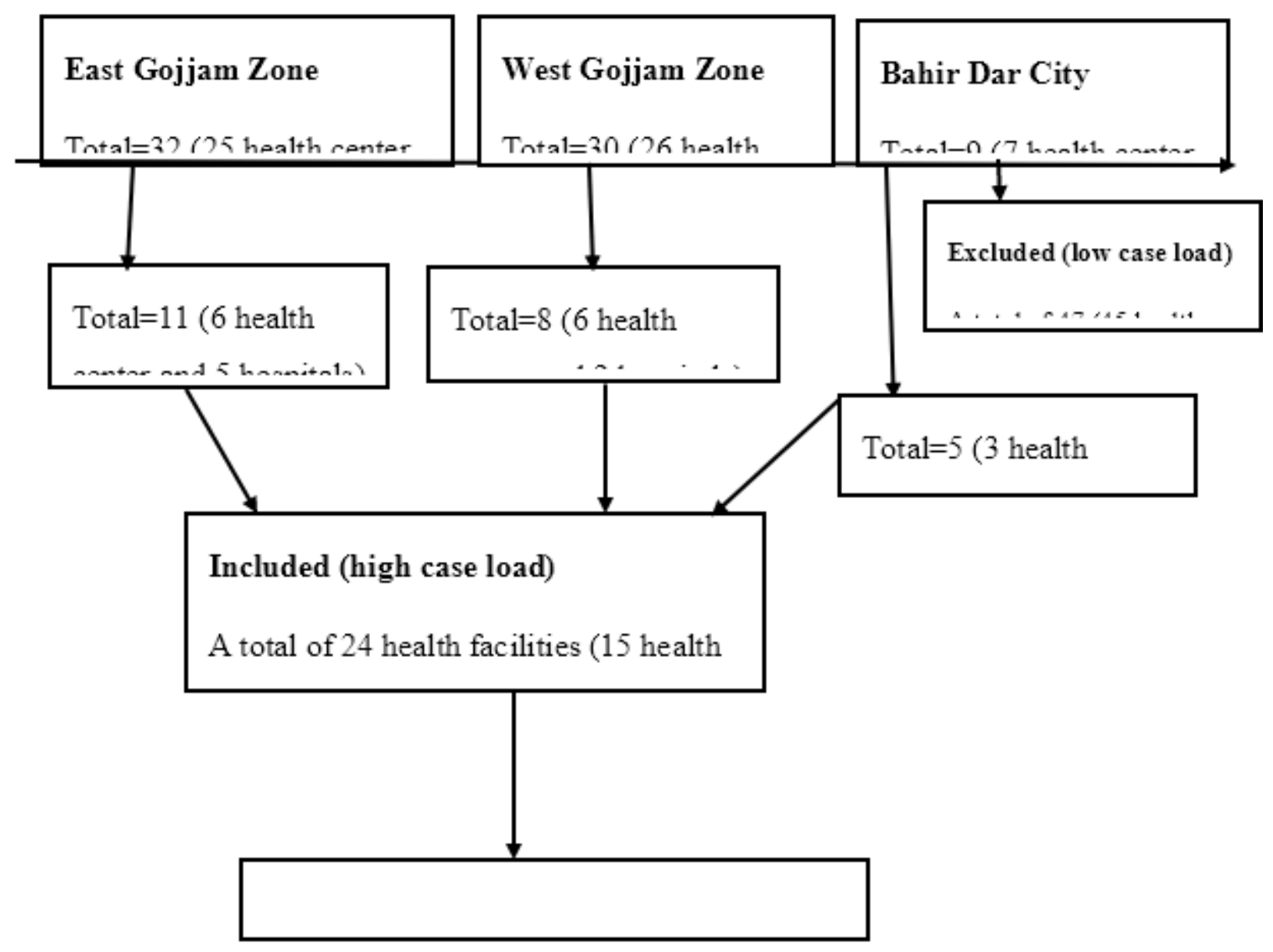

Figure 1

Sampling techniques of delayed HIV diagnosis among newly diagnosed people living with HIV in northwest Ethiopia, 2019 